\title{
A reconfigurable high-gain metal-graphene printed dipole antenna for Wi-Fi and LTE applications
}

Roghaye Ebadzadeh

Islamic Azad University Urmia Branch

Pejman Mohammadi ( $\nabla$ pmohamady@yahoo.com )

Islamic Azad University Urmia Branch https://orcid.org/0000-0001-6423-7910

Mahdi Zavvari

Islamic Azad University Urmia Branch

\section{Research Article}

Keywords: Printed Dipole antenna, Graphene, Reconfigurable, Wi Fi, LTE

Posted Date: March 15th, 2021

DOI: https://doi.org/10.21203/rs.3.rs-268254/v1

License: (1) This work is licensed under a Creative Commons Attribution 4.0 International License.

Read Full License 


\title{
A reconfigurable high-gain metal-graphene printed dipole antenna for Wi-Fi and LTE applications
}

\author{
Roghaye Ebadzadeh ${ }^{1}$, Pejman Mohammadi ${ }^{1}$ and Mahdi Zavvari ${ }^{1}$
}

\begin{abstract}
This study presents the design and construction of a reconfigurable c-shaped dipole antenna for Wi-Fi and LTE bands. It consists of two nested c-shape resonators located inside each of the wings of the c-dipole patch antennas. The mentioned resonators have been used due to their inductive and capacitive effects. The reconfigurable property of the proposed antenna has been achieved with two graphene layers which are deposited on two gaps over the patch antennas. The graphene layers adjust the return loss of the proposed antenna into the desired band. These graphene layers are examined with different chemical potentials so that the antenna return loss changes over the. The simulation and measurement results show that the gain of the antenna is higher than $5 \mathrm{~dB}$ for both LTE and Wi-Fi applications. A good agreement is recognized between the measured and simulation results.
\end{abstract}

Keywords: Printed Dipole antenna, Graphene, Reconfigurable, Wi-Fi, LTE

\section{Introduction}

Given the new applications of radio systems, designing the most effective antenna seems to be indispensable. The Wi-Fi can be regarded as the most popular technology in the field of wireless local area networks that allows high-speed internet or network connections using radio waves [1]. The Long term evolution (LTE) covers three bands, where the lower band includes frequency range of (698$966 \mathrm{MHz})$, the middle band in the range of $(1.427-2.69 \mathrm{GHz})$ and higher band in the range of (3.4$3.8 \mathrm{GHz}$ ) [2]. Graphene has been constructed as two-dimensional material in 2004, which has attracted increasing attention in recent years due it's exotic properties such as high mobility carrier, low resistivity, high conductivity, chemical stability, mechanical flexibility, and so on [3], [4].

According to the development of knowledge regarding radio systems in wireless communications, there have been many studies about graphene antennas [5]. Presently, the use of nanomaterials such as graphene in designing antennas, including the antennas with small dimensions, the electrically tunable, reconfigurable, and beamforming have grasped the attention of many researchers. Graphene can be used directly as a radiation element, or for tuning the radiation properties of the element [6].

However, the radiation efficiency of the graphene is usually limited due to its significant loss [7]. To improve the radiation efficiency, hybrid metal-graphene structures have been proposed [7], [8], [9], [10].

In some other structures, graphene is used to improve the radiation of antennas. In this case, graphene is used as a coating of radiation metal, thereby improving its radiation pattern and efficiency [11].

The concept of reconfigurable antenna denotes the changes in frequency characteristics, radiation patterns, or polarization of the antenna that can be implemented without changing the physical size and

E-mail:

Pejman Mohammadi:

pmohamady@yahoo.com

1. Dept. of Electrical and Electronic Engineering, Urmia Branch, Islamic Azad University, Urmia, Iran 
dimensions of the antenna using these techniques [12]. The antenna structure of graphene could be flexible and lightweight [13], [14]. Graphene has the property that, it exhibits different resonance frequencies when the applied chemical potential is changed. Also, changing the resistance of the grapheme in different DC-bias, changes the input impedance of the antenna, thus shifting the resonance frequency of the antenna. In the proposed manuscript the aforementioned property of graphene is applied to the metal-graphene antenna for achieving reconfigurable structure.

Performance analysis of the hybrid metal-graphene frequency reconfigurable antenna in the microwave regime has been proposed by Alvarez et al [15]. In the mentioned study, the performance of the use of graphene in the frequency of reconfigurable antenna has been evaluated using the simulation of two metal-graphene antennas for Wi-Fi and LTE applications. Accordingly, graphene is not only another choice to an RF switch, however, it can also be used for fabricating the radiating antenna itself [15].

In [16] a planar antenna with voltage-controlled frequency tuning based on few-layer graphene was proposed. They showed that by using the pad of few-layer graphene flakes at the input of shorted microstrip stubs, it is possible to obtain the optimized voltage-controlled tunable patch antenna.

In the present study, at first, the c-dipole antenna was designed with two nested c-shape resonators located inside each of the wings of the c-dipole antenna under non-graphene condition. To feed the cdipole antenna, a microstrip integrated balun [17], [18] was used on the backside of the Rogers 4003 substrate. The integrated balun is used for impedance matching of the antenna with coaxial cable. In the next step, the graphene was added to the dipole antenna. The antenna simulation and measurement results with and without graphene are provided and also the simulation results with different chemical potentials are illustrated. Some features of the proposed antenna are compared with those of similar antennas.

\section{Design of Reconfiguration Antenna}

The geometric structure of the proposed antenna is presented in Fig.1.The top view (Fig.1a) of the structure includes two nested c-shape resonators which are located inside each of the wings of the cdipole patch antenna. Two narrow strips of graphene are used to connect the resonators.

The overall size of the proposed c-dipole antenna is $49 \times 90 \times 0.8 \mathrm{~mm} 3$. An integrated balun in the form of a $\Gamma$-shape microstrip line is printed on the backside of the substrate (Fig. 1b). The proposed antenna can operate at 1-4 GHz. This operating bandwidth covers Wi-Fi and LTE. The coaxial cable is connected to the antenna's feed line through a ground plane that is perpendicular to an antenna and located underneath it. The parametric values of the proposed antenna are summarized in Table.1. The proposed antenna was etched on the Rogers 4003 substrate with a thickness of $0.8 \mathrm{~mm}$ a dielectric constant of 3.55 , and a loss tangent of 0.0027 . In the proposed design, a temperature of $300 \mathrm{~K}$, graphene thickness of $10 \mathrm{~nm}$, chemical potential coefficient of 0.2 , and a relaxation time of 1 hour were applied.

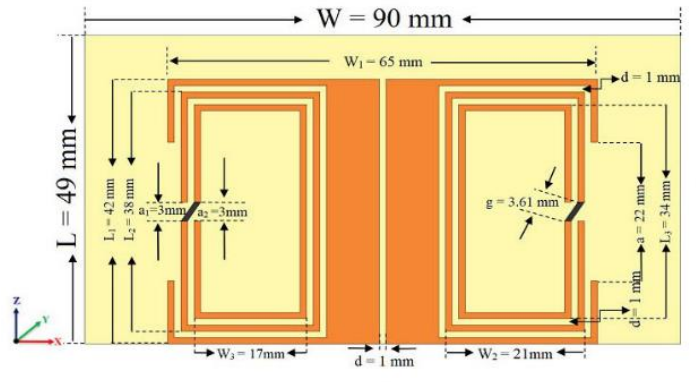

(a)

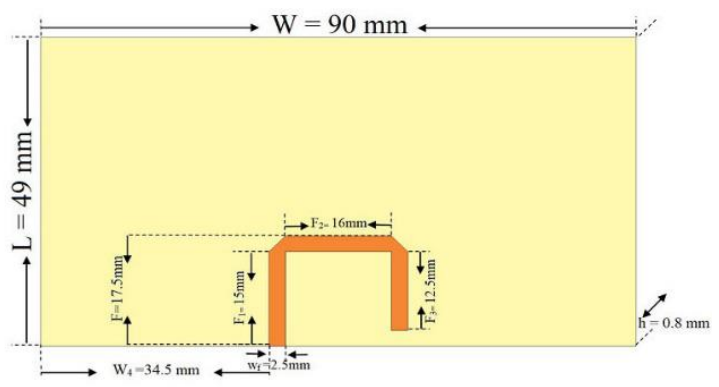

(b)

Fig. 1. The proposed antenna (a) front view, (b) back view. 
A reconfigurable high-gain metal-graphene printed dipole antenna ........

Table1: The optimized parameters of the proposed antenna.

\begin{tabular}{cccccc}
\hline $\begin{array}{c}\text { Paramete } \\
\text { r }\end{array}$ & Value & Parameter & Value & Parameter & $\begin{array}{c}\text { Val } \\
\text { ue }\end{array}$ \\
\hline $\mathrm{W}$ & 90 & $\mathrm{~L}_{1}$ & 42 & $\mathrm{~L}_{2}$ & 38 \\
$\mathrm{~L}$ & 49 & $\mathrm{~W}_{2}$ & 21 & $\mathrm{~L}_{3}$ & 34 \\
$\mathrm{~W}_{1}$ & 65 & $\mathrm{~W}_{3}$ & 17 & $\mathrm{a}$ & 22 \\
$\mathrm{~h}$ & 0.8 & $\mathrm{~F}_{1}$ & 15 & $\mathrm{a}_{1}$ & 3 \\
$\mathrm{~W}_{\mathrm{f}}$ & 2.5 & $\mathrm{~F}_{2}$ & 16 & $\mathrm{a}_{2}$ & 3 \\
$\mathrm{~g}$ & 3.61 & $\mathrm{~F}_{3}$ & 12.5 & $\mathrm{~d}$ & 1 \\
$\mathrm{~F}$ & 17.5 & $\mathrm{~W}_{4}$ & 34.5 & & \\
\hline
\end{tabular}

The c-shaped resonators and the equivalent circuit model [19] are shown in Fig.2. The c-shaped resonator acts as a parallel LC circuit near the resonance frequency. The graphene can be represented by the equivalent resistance in.
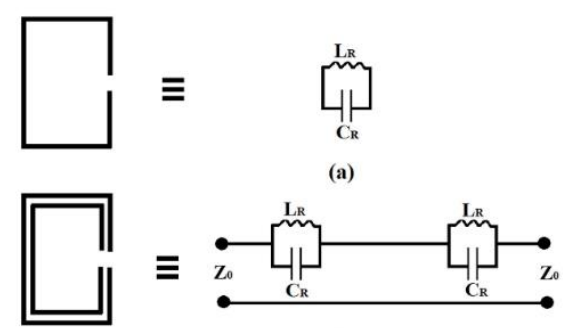

(b)
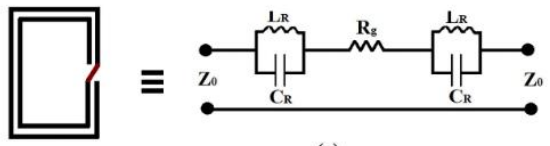

(c)

Fig. 2. (a) The c-shaped resonator and the equivalent circuit model, (b) Two c-shaped resonators and the equivalent circuit model without graphene, (c) with graphene

\section{Results and Discussion of the Antenna}

Graphene strips in the proposed antenna firstly have been used for adjusting the return loss, then by changing the chemical potential of it the reconfigurable property of the antenna has been achieved. Therefore, the simulation of the proposed antenna with and without graphene is investigated separately. Two proposed antennas are compared in terms of return loss, gain, and pattern. The simulation and measurement results obtained from the CST software and the N5242A network analyzer respectively.

\subsection{Return loss}

The simulation results of the proposed antenna are provided in Fig.3. According to this figure, the antenna with graphene covers more frequency in Wi-Fi and LTE application. The measurement setup of the proposed antenna is presented in Fig.4.The simulations and measurements of the S11 for the proposed antenna without and with graphene are provided in Fig.5 and Fig.6, respectively. 


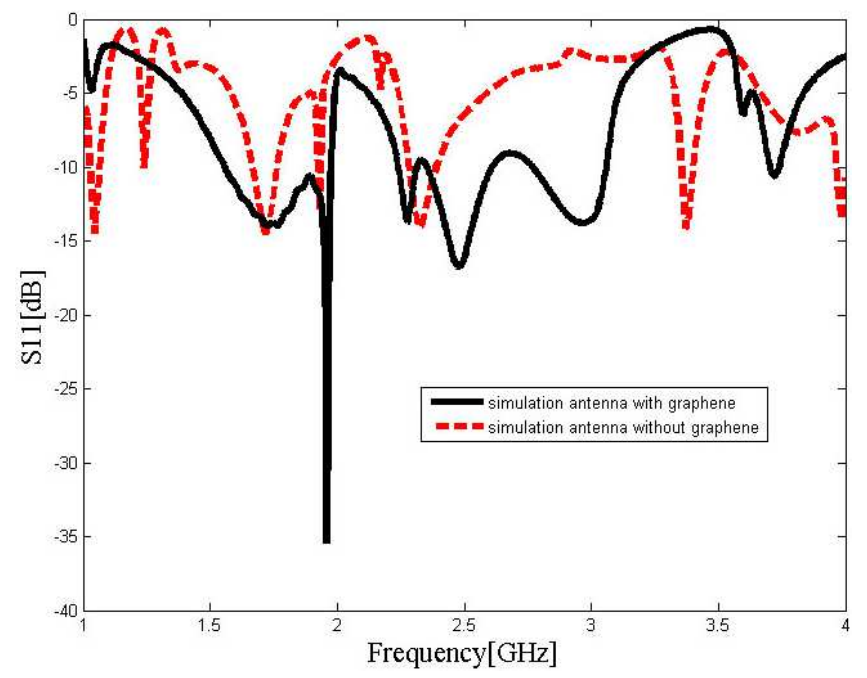

Fig. 3. The simulation results of S11 for the proposed antenna.

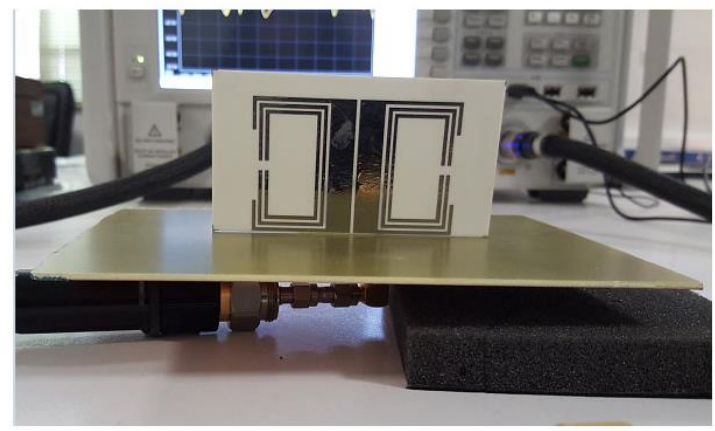

(a)

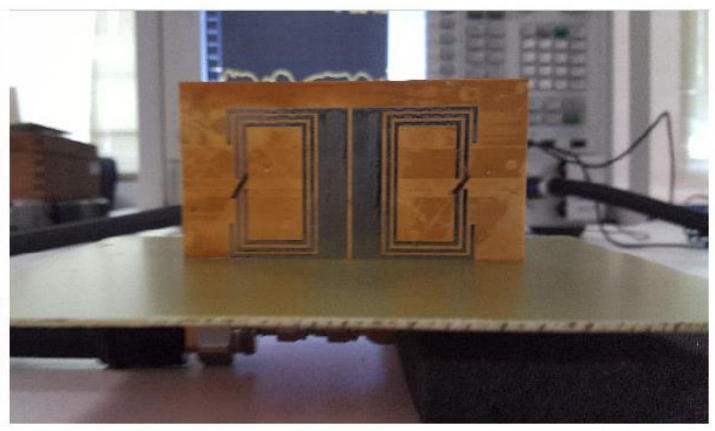

(b)

Fig 4. The measurement setup of the proposed antenna (a) without graphene, (b) with graphene.

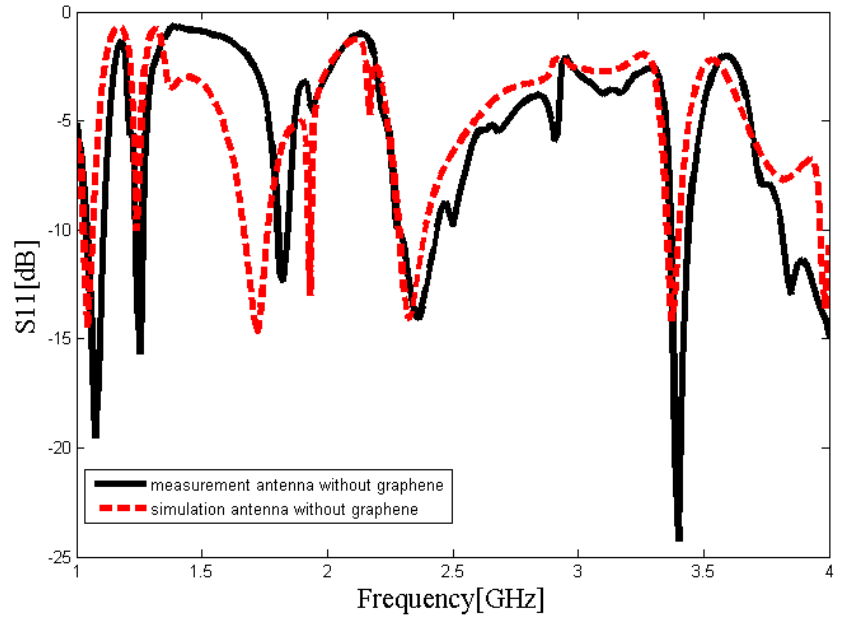

Fig 5. The simulation and measurement results of S11 for the proposed antenna without graphene. 


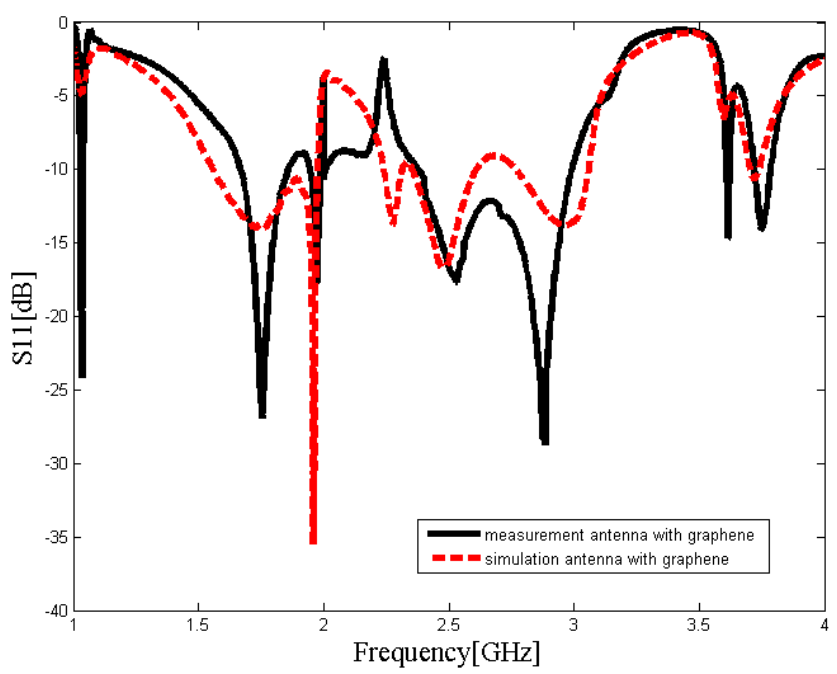

Fig6. The simulation and measurement results of S11 for the proposed antenna with graphene.

By changing the chemical potential of the graphene antenna, the resonant frequency changes, attaining frequency reconfiguration is shown in Fig.7.

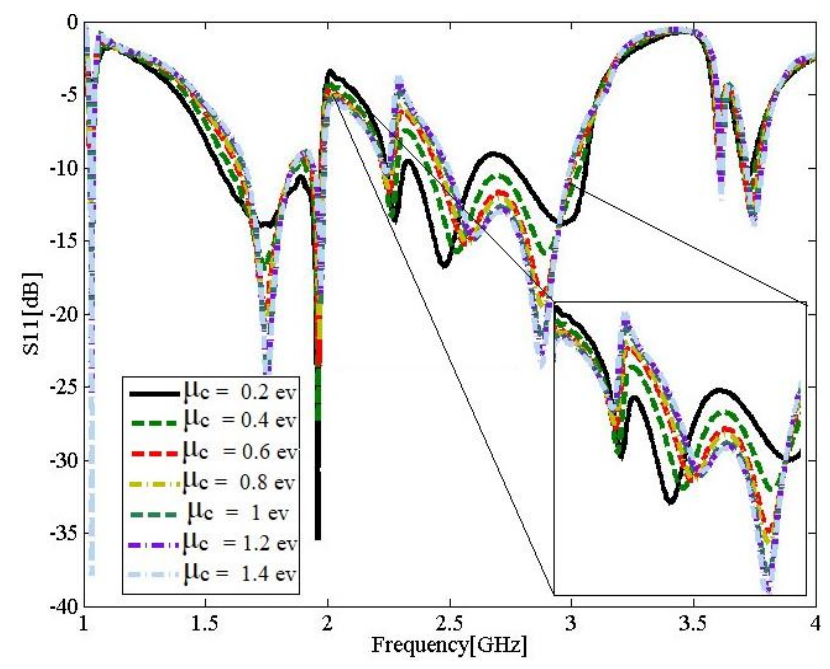

Fig. 7. The simulation results of S11 versus frequency for different chemical potentials.

Fig. 8 shows the simulation results of S11 versus frequency, for different values of the graphene resistance. As expected, changing the equivalent resistance of the graphene changes the input impedance of the antenna, thus shifting the resonance frequency of the antenna. As shown in Fig. 8, the antenna operates at the frequency of $2.4 \mathrm{GHz}$ when the graphene resistance is $\mathrm{R}=1000 \Omega$ and decreases to 2.29 $\mathrm{GHz}$ when the graphene resistance is $\mathrm{R}=100 \Omega$. The resulting overall frequency shift is $110 \mathrm{MHz}$. 


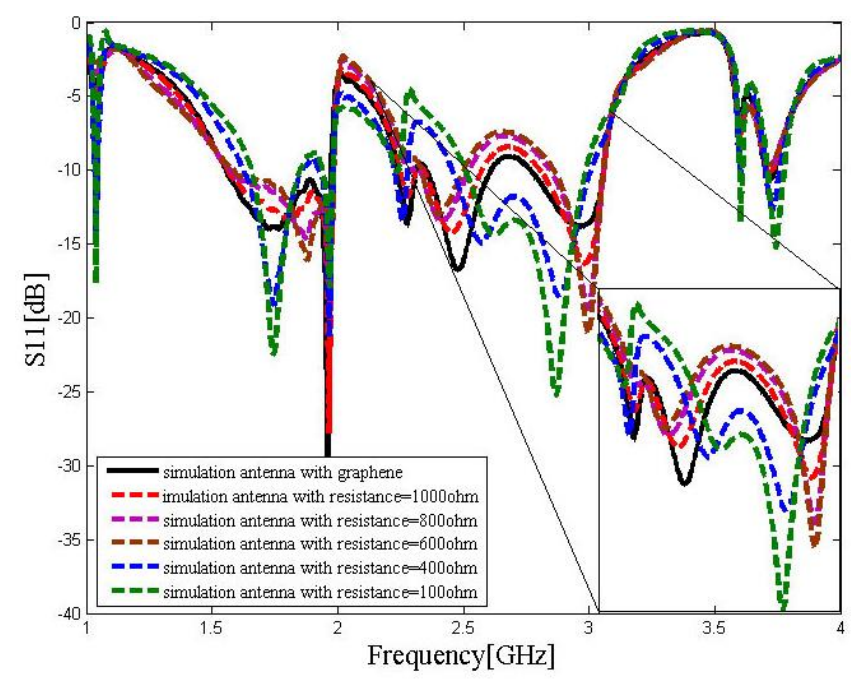

Fig. 8. The simulation results of S11 versus frequency, for different values of the graphene equivalent resistance.

\subsection{Gain}

The measurement and simulation gains of the antenna are presented in Fig.9. The measurement gains of the antenna with graphene are $5 \mathrm{~dB}, 6.1 \mathrm{~dB}, 5.2 \mathrm{~dB}, 7.1 \mathrm{~dB}$, and $6.5 \mathrm{~dB}$ at $1.1 \mathrm{GHz}, 1.8 \mathrm{GHz}, 2.4 \mathrm{GHz}$, $2.8 \mathrm{GHz}$, and $3.6 \mathrm{GHz}$ respectively. The measurement gains of the antenna without graphene are $3 \mathrm{~dB}, 5$ $\mathrm{dB}, 6.1 \mathrm{~dB}, 6.9 \mathrm{~dB}$, and $6.5 \mathrm{~dB}$ at $1.1 \mathrm{GHz}, 1.3 \mathrm{GHz}, 1.8 \mathrm{GHz}, 2.3 \mathrm{GHz}$, and $3.3 \mathrm{GHz}$ respectively.

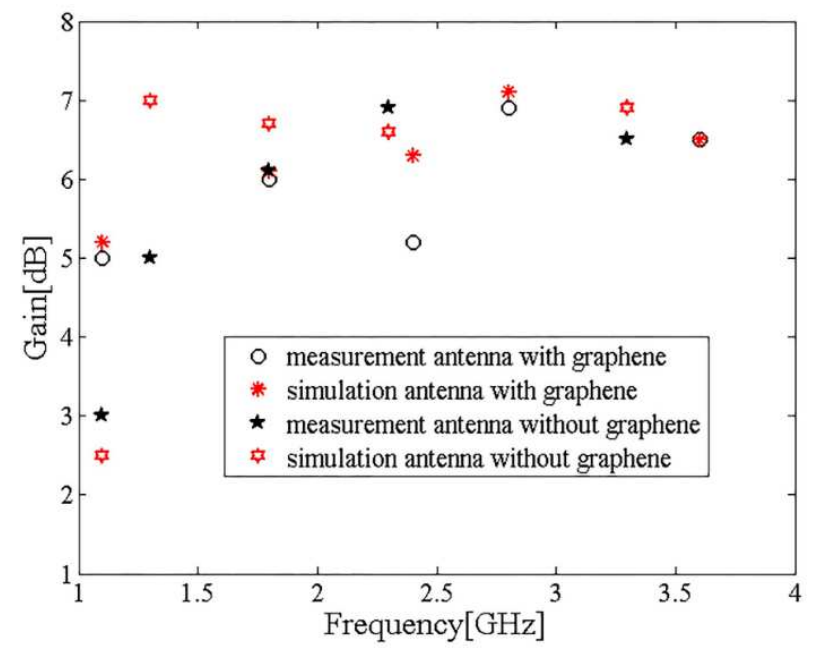

Fig. 9. The simulation and measurement results of the gain for the proposed antennas.

\subsection{Radiation Pattern}

The measurement and simulation results of the radiation pattern for the proposed antenna without and with graphene are summarized in Fig.10 and Fig.11 respectively. As it is seen in Fig 11, by adding the graphene, the radiation pattern changes slightly, also the radiation pattern has an almost homogeneous pattern on frequencies of $1.3 \mathrm{GHz}, 1.8 \mathrm{GHz}, 2.3 \mathrm{GHz}, 2.4 \mathrm{GHz}, 2.8 \mathrm{GHz}, 3.3 \mathrm{GHz}$ and, $3.6 \mathrm{GHz}$ in the E 
plane as it is expected for this antenna.
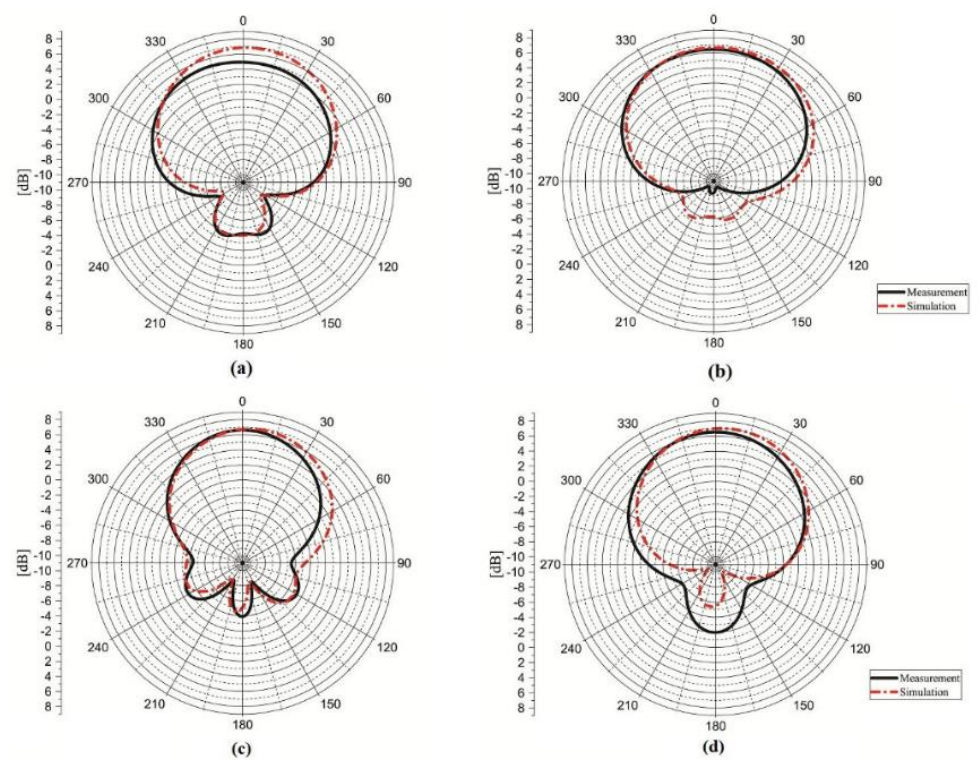

Fig. 10. Measurement and Simulation results of the radiation pattern of the antenna without graphene. (a) $1.3 \mathrm{GHz},(\mathrm{b}) 1.8 \mathrm{GHz},(\mathrm{c}) 2.3 \mathrm{GHz},(\mathrm{d}) 3.3 \mathrm{GHz}$.
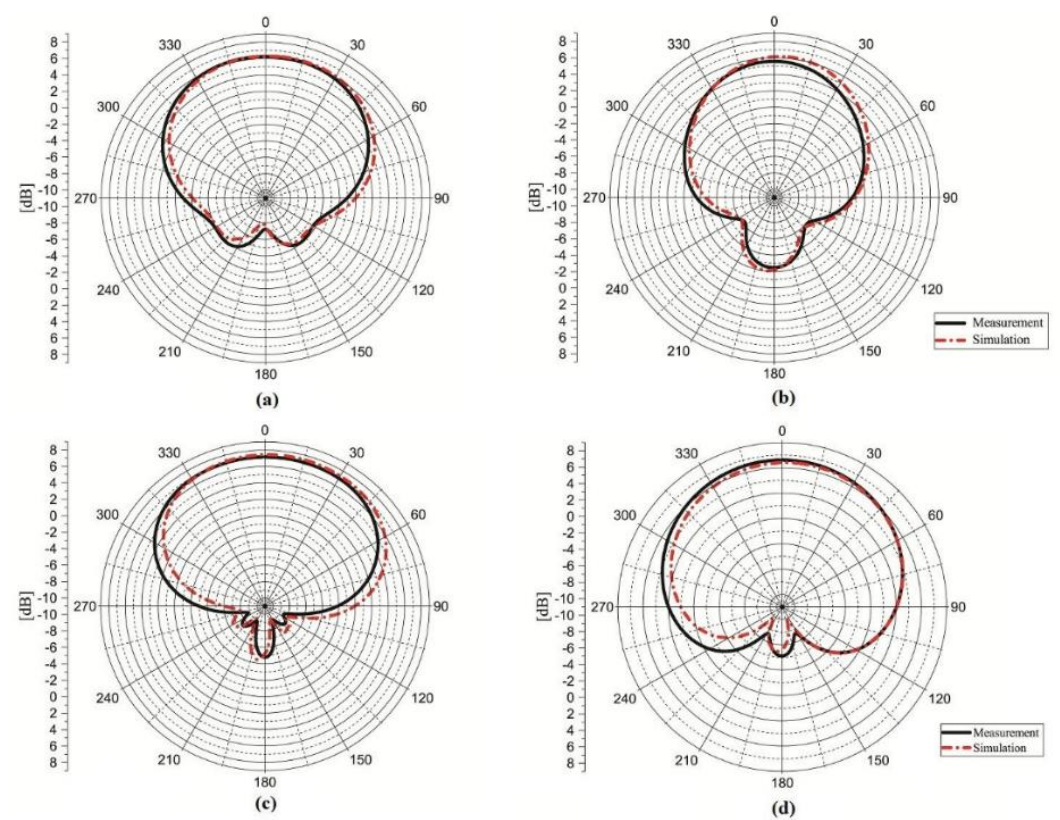

Fig. 11. Measurement and Simulation results of the radiation pattern of the antenna with graphene. (a) $1.8 \mathrm{GHz},(\mathrm{b}) 2.4 \mathrm{GHz},(\mathrm{c}) 2.8 \mathrm{GHz},(\mathrm{d}) 3.6 \mathrm{GHz}$.

\subsection{Surface current}

Fig.12 shows the current distribution for the proposed antenna at two-state without and with graphene at $2.5 \mathrm{GHz}$. As it is expected the current distribution is stronger when the graphene is set to the existed state, Fig. 12b, the current is allowed to flow, through the strips. However, when the graphene is set to the nonexistence state, Fig. 9a, the currents are not flow through the strips but are diverted around them. This 
makes the currents travel longer paths, which is equivalent to increasing inductance effect and therefore the antenna resonance is found at a lower frequency.
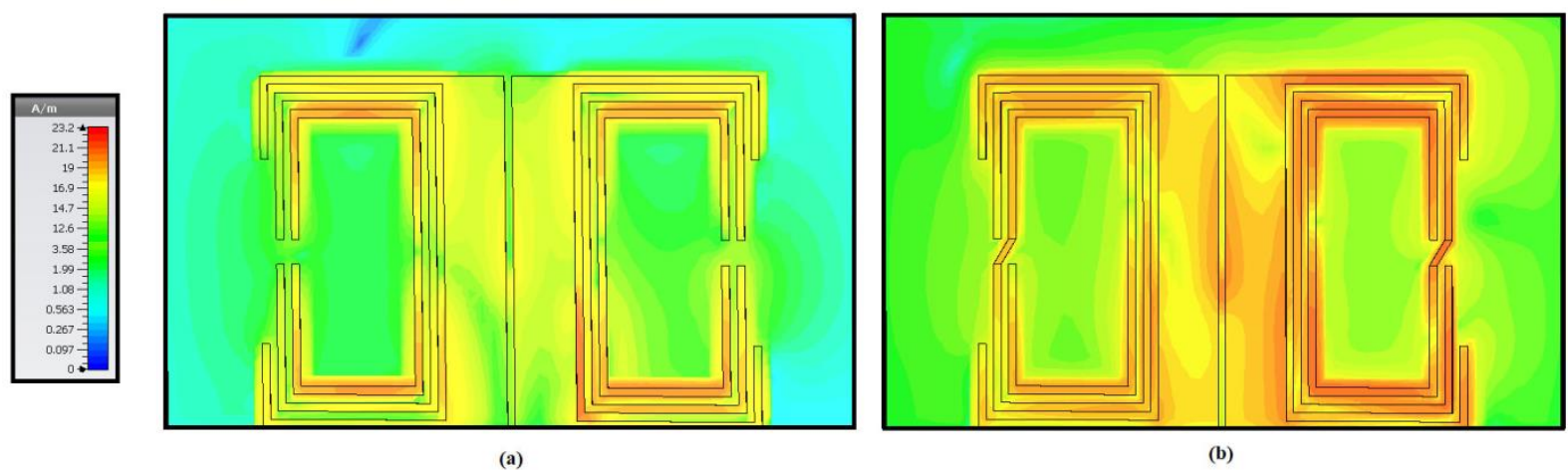

(b)

Fig. 12. Surface current distribution antenna (a) without graphene (b) with graphene.

\subsection{Comparisons}

Table. 2 presents a comparison of the proposed antenna with similar antennas [15], [16]. In order to have an exact comparison, we try to do it with a graphene-metal-based antenna. In [15] two di $\square$ erent structures are used for Wi-Fi and LTE. The first structure for Wi-Fi consists of a central rectangular patch with two graphenes added on the sides and the second structure for LTE consists of a microstrip patch antenna with inset notches on the edges, where graphene strips are added in those spaces. The structure in [16] consists of the microstrip line, patch, graphene, stub, and shorting via. The gain of the proposed antenna is higher than both similar antennas, and also its structure is simple in comparison with them.

Table2: Comparisons between this work and other antennas.

\begin{tabular}{ccccc}
\hline Reference & $\varepsilon_{\mathrm{r}}$ of the substrate & Frequency $(\mathrm{GHz})$ & Size $\left(\mathrm{mm}^{3}\right)$ & Gain $(\mathrm{dB})$ \\
\hline [15] WIFI application & Polystyrene (PS),2.4 & $2.4,3.6,5$ & $23 \times 14.7 \times 2.1$ & $-3.4,1.3,5.2$ \\
[15] LTE application & Polystyrene (PS),2.4 & $1.8,2.1,2.6,3.6$ & $39 \times 22 \times 2.1$ & $-1.6,-0.7,-3.3,3.9$ \\
[16] & Taconic RF35,3.5 & $5-5.2$ & $20 \times 15 \times 1.52$ & 2.38 \\
This work & Rogers 4003,3.55 & $1.1,1.8 .2 .4,2.8,3.6$ & $90 \times 49 \times 0.8$ & $5,6.1,5.2,7.1,6.5$ \\
\hline
\end{tabular}

\section{Conclusion}

The new design and topology of a reconfigurable metal-graphene dipole antenna are proposed. In order to show the role of graphene two structures are designed and fabricated. The comparison results with similar antennas indicated that the proposed antenna not only has a simple structure but also shows a higher gain. The reconfigurable ability of graphene with different chemical-potential is exhibited. The measurement return loss and radiation properties verify that it is suitable for Wi-Fi and LTE applications.

\section{ACKNOWLEDGMENTS}

The authors would like to express their gratitude to the Microwave Laboratory of the Islamic Azad University of Urmia for providing the PNA-X network analyzer system (N5242A).

\section{Declarations}

The authors have no conflicts of interest to declare that are relevant to the content of this article. 
A reconfigurable high-gain metal-graphene printed dipole antenna .........

\section{References}

[1] Desai A, Upadhyaya T, Palandoken M, Gocen C. Dual band transparent antenna for wireless MIMO system applications. Microwave and Optical Technology Letters. 2019 Jul;61(7):1845-56.

[2] Hasan MM, Faruque MR, Islam MT. Dual band metamaterial antenna for LTE/bluetooth/WiMAX system. Scientific reports. 2018 Jan 19;8(1):1-7.

[3] Akbari M, Khan MW, Hasani M, Björninen T, Sydänheimo L, Ukkonen L. Fabrication and characterization of graphene antenna for low-cost and environmentally friendly RFID tags. IEEE Antennas and Wireless Propagation Letters. 2015 Nov 9; 15:1569-72.

[4] Lamminen A, Arapov K, de with G, Haque S, Sandberg HG, Friedrich H, Ermolov V. Graphene-flakes printed wideband elliptical dipole antenna for low-cost wireless communications applications. IEEE Antennas and Wireless Propagation Letters. 2017 Mar 20; 16:1883-6.

[5] Zakrajsek L, Einarsson E, Thawdar N, Medley M, Jornet JM. Design of graphene-based plasmonic nano-antenna arrays in the presence of mutual coupling. In2017 11th European Conference on Antennas and Propagation (EUCAP) 2017 Mar 19 (pp. 1381-1385). IEEE.

[6] Mencarelli D, Dragoman M, Pierantoni L, Rozzi T, Coccetti F. Design of a coplanar graphene-based nano-patch antenna for microwave application. In2013 IEEE MTT-S International Microwave Symposium Digest (MTT) 2013 Jun 2 (pp. 1-4). IEEE.

[7] Radwan AH, D'Amico M, Gentili GG. Reconfigurable THz Yagi antenna based on hybrid graphene-metal layout. In2014 Loughborough Antennas and Propagation Conference (LAPC) 2014 Nov 10 (pp. 671-675). IEEE.

[8] Zhao WS, Wang XC, Hu J. Frequency-and beam-reconfigurable THz Fabry-Perot antenna based on hybrid Cugraphene HIS. In2015 IEEE MTT-S International Microwave Workshop Series on Advanced Materials and Processes for RF and THz Applications (IMWS-AMP) 2015 Jul 1 (pp. 1-3). IEEE.

[9] Cheng X, Yao Y, Qu SW, Wu Y, Yu J, Chen X. Circular beam-reconfigurable antenna base on graphene-metal hybrid. Electronics Letters. 2016 Feb 25;52(7):494-6.

[10] Wang X, Zhao WS, Hu J, Zhang T. A novel tunable antenna at THz frequencies using graphene-based artificial magnetic conductor (AMC). Progress in Electromagnetics Research. 2013; 41:29-38.

[11] Azizi MK, Ksiksi MA, Ajlani H, Gharsallah A. Terahertz graphene-based reconfigurable patch antenna. Progress in Electromagnetics Research. 2017; 71:69-76.

[12] Boufrioua A. Frequency reconfigurable antenna designs using PIN diode for wireless communication applications. Wireless Personal Communications. 2020 Feb;110(4):1879-85.

[13] Mehta B, Zaghloul M. Tuning nano antenna with graphene. In2013 IEEE Antennas and Propagation Society International Symposium (APSURSI) 2013 Jul 7 (pp. 130-131). IEEE.

[14] Llatser I, Kremers C, Cabellos-Aparicio A, Jornet JM, Alarcón E, Chigrin DN. Graphene-based nano-patch antenna for terahertz radiation. Photonics and Nanostructures-Fundamentals and Applications. 2012 Oct 1;10(4):353-8.

[15] Alvarez CN, Cheung R, Thompson JS. Performance analysis of hybrid metal-graphene frequency reconfigurable antennas in the microwave regime. IEEE Transactions on Antennas and Propagation. 2017 Feb 16;65(4):1558-69.

[16] Bellucci S. Graphene-based tunable microstrip attenuators and patch antenna. In2017 International Semiconductor Conference (CAS) 2017 Oct 11 (pp. 19-27). IEEE.

[17] Rezvani M, Mohammadi P. A dual-polarized reflector antenna with $\lambda / 2$ printed dipoles for femtocell applications. Journal of Instrumentation. 2019 Feb 4;14(02): P02004.

[18] Mohammadi P, Rezvani M, Siahy T. A circularly polarized wide-band magneto-electric dipole antenna with simple structure for BTS applications. AEU-International Journal of Electronics and Communications. 2019 Jun 1; 105:92-7.

[19] Belbachir AK, Boussouis M, Amar Touhami N. High-performance LPF using coupled C-shape DGS and radial 
stub resonators for microwave mixer. Progress in Electromagnetics Research. 2016; 58:97-103.

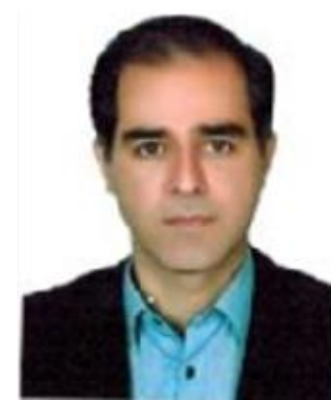

Pejman Mohammadi. was born in 1973 in Tehran, Iran. He received Ph.D. in Electrical Engineering from the Middle East Technical University Turkey. Since 2001, he has been with the Department of Electrical Engineering, Islamic Azad University of Urmia, Iran where he is currently Assistant Professor. His research interests include microwave component SIW, microstrip antennas, small antennas for wireless communications, and reconfigurable structures.

Roghaye ebadzadeh. was born in 1987 in Tehran, Iran. She received her B.Sc. degree in Electrical Engineering from Azad University, Urmia Branch and M.Sc. degree in Electrical Engineering from Department of Electrical Engineering, Science and Research Branch, Islamic Azad University, West Azerbaijan, Iran. She is currently Ph.D. Student at the Islamic Azad University of Urmia West Azerbaijan, Iran. Her research interests include microstrip antennas, Diplexer, a monopole antenna, and an array antenna.

Mahdi Zavvari. is an assistant professor. He received the B.S. degree from Tabriz University in 2004 and M.S. and Ph.D. degrees from Islamic Azad University Science and research branch in 2007 and 2012, respectively all in electronic engineering. He is currently an assistant professor of the Urmia branch, Islamic Azad University, and is the head of the Advanced optical and microwave device lab in the electrical engineering faculty. His research interest is on quantum dot/ring photodetectors, single-photon detectors, avalanche photodiodes, and lasers. 
Figures

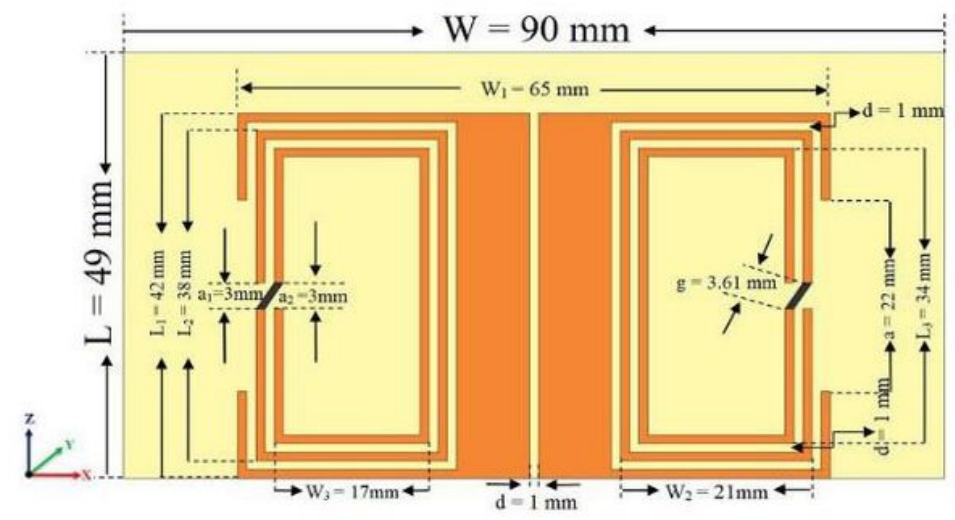

(a)

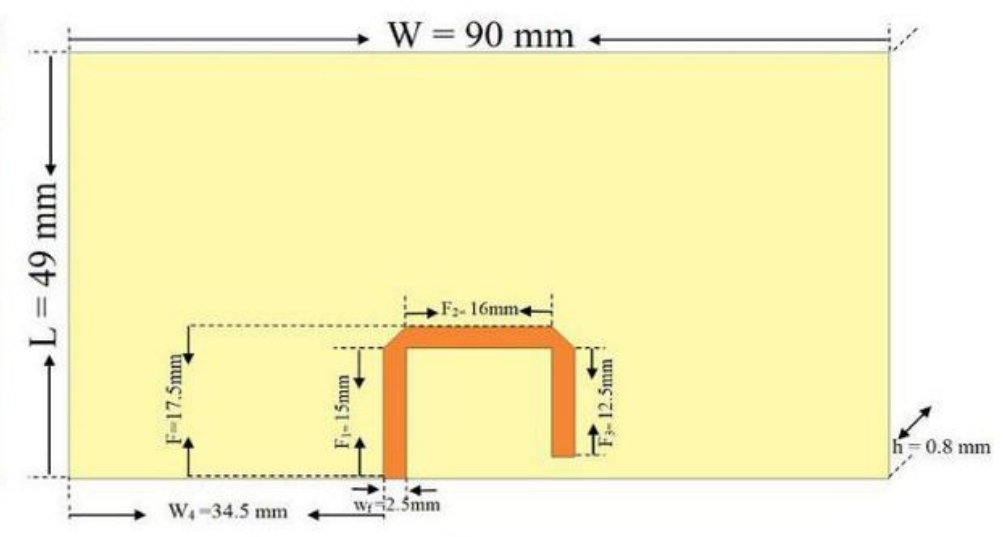

(b)

Figure 1

The proposed antenna (a) front view, (b) back view.

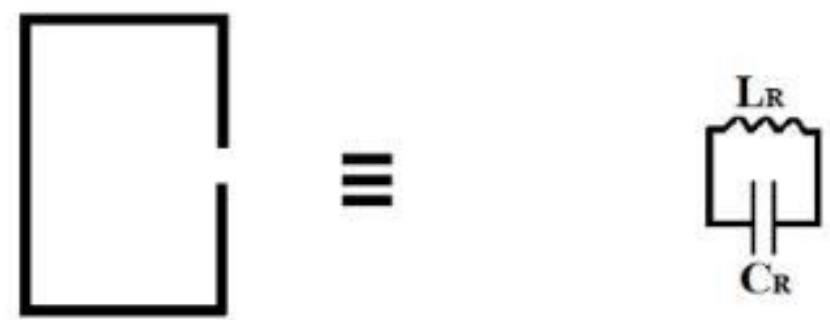

(a)
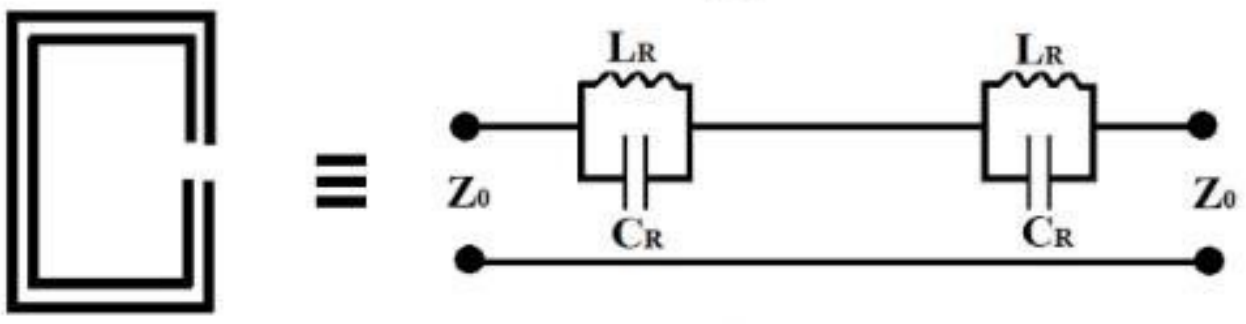

(b)
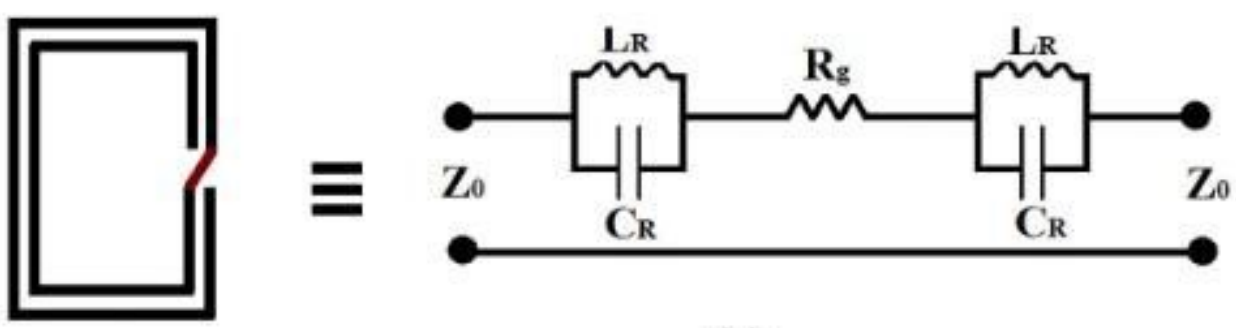

(c)

Figure 2 
(a) The c shaped resonator and the equivalent circuit model, (b) Two $c$ shaped resonators and the equivalent circuit model without graphene, (c) with graphene

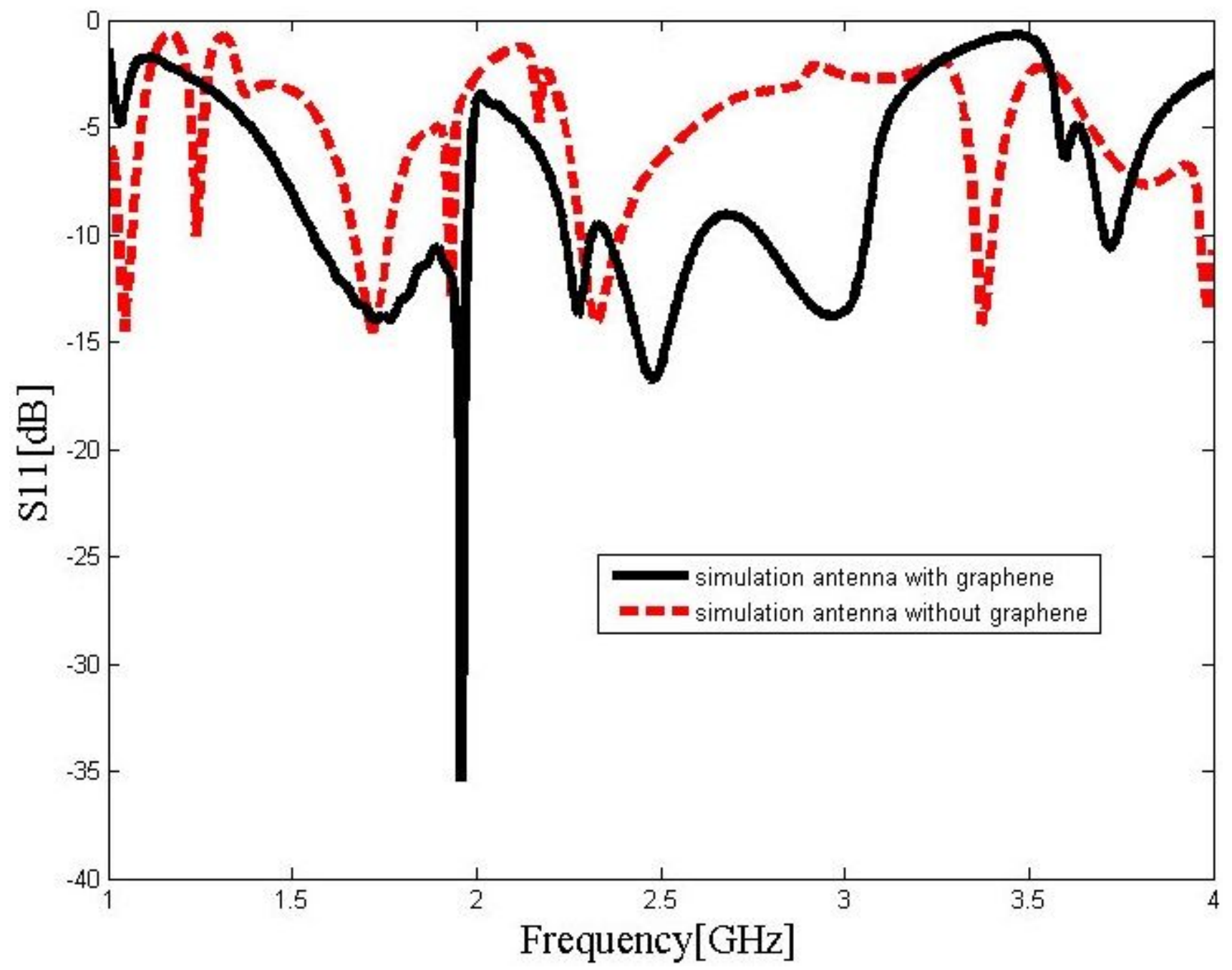

Figure 3

The simulation results of S11 for the proposed antenna.

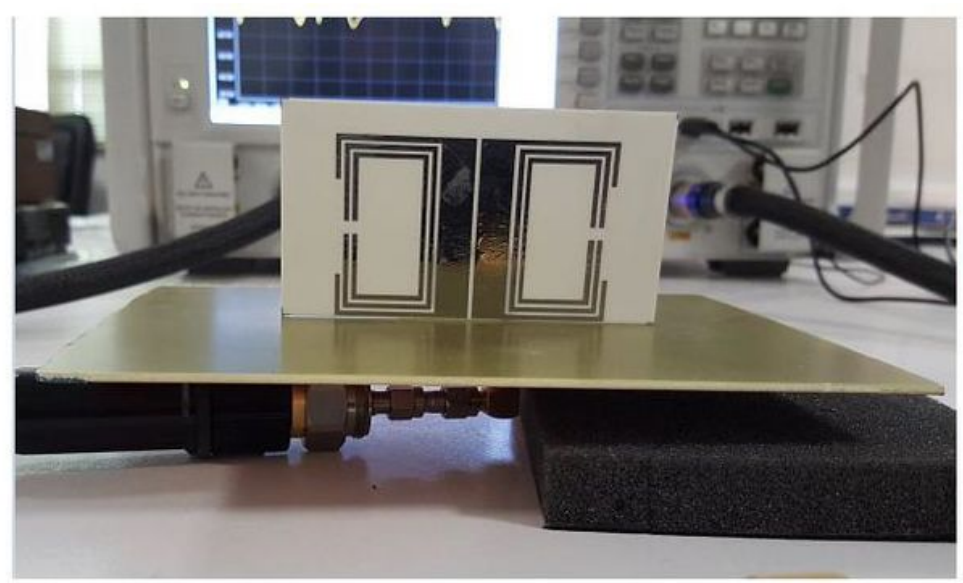

(a)

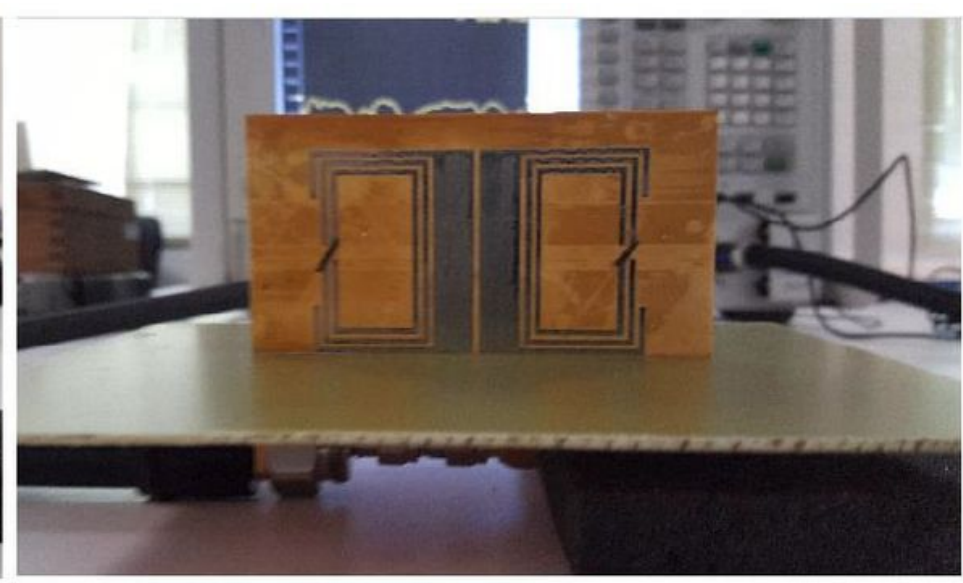

(b)

Figure 4 
The measurement setup of the proposed antenna (a) without graphene, (b) with graphene.

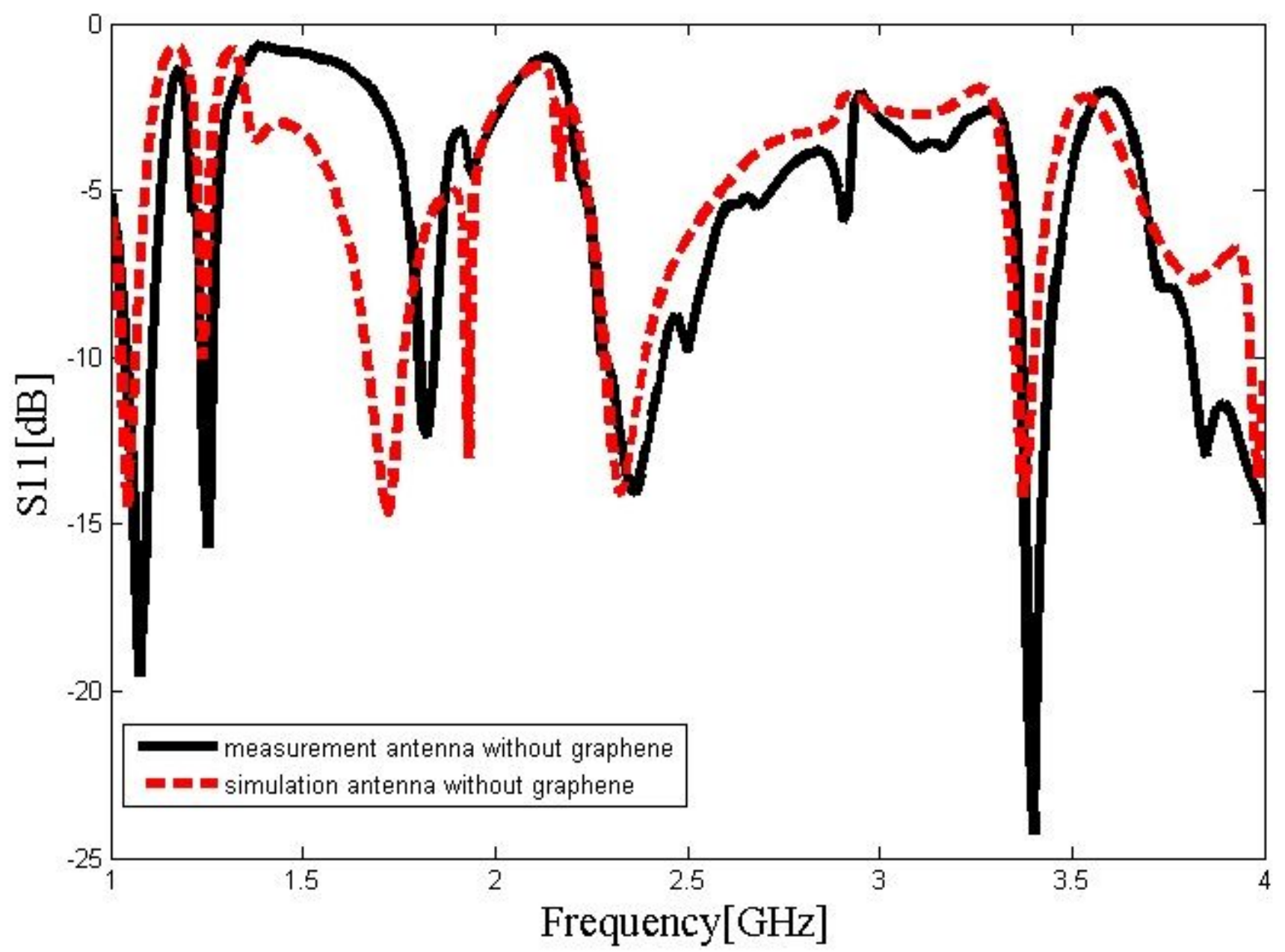

Figure 5

The simulation and measurement results of $\mathrm{S} 11$ for the proposed antenna without graphene. 


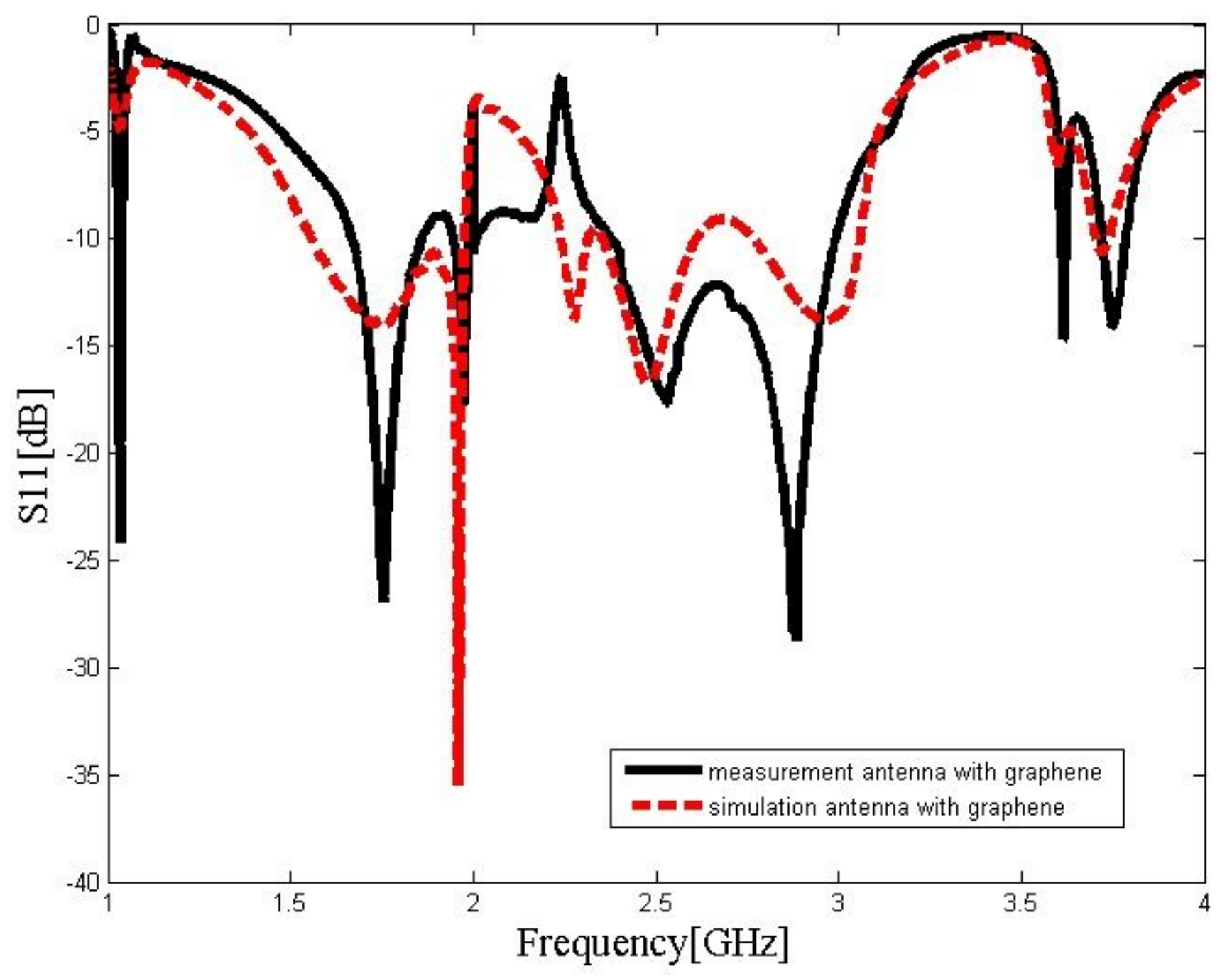

Figure 6

The simulation and measurement results of $\mathrm{S} 11$ for the proposed antenna with graphene. 


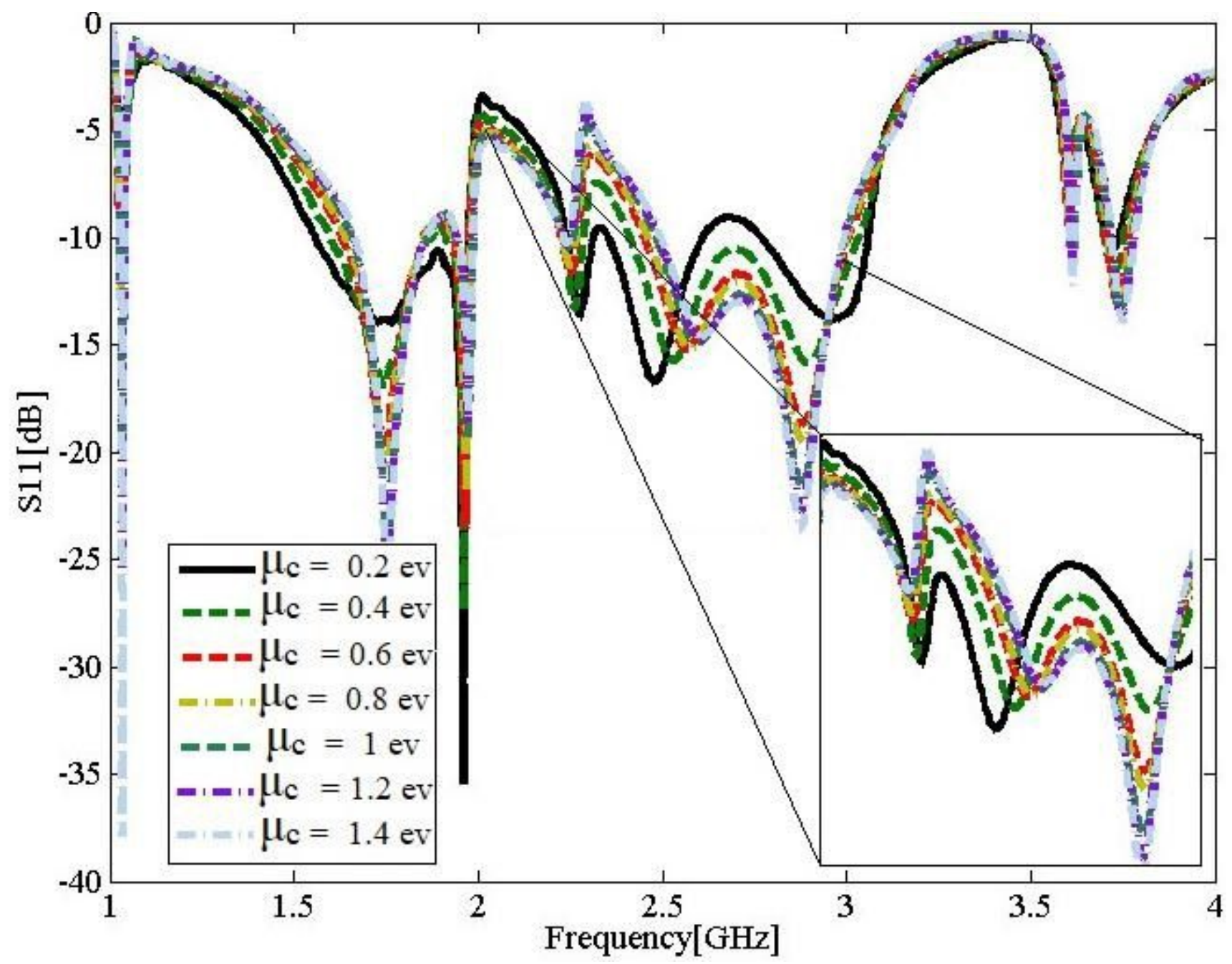

Figure 7

The simulation results of S11 versus frequency for different chemical potentials. 


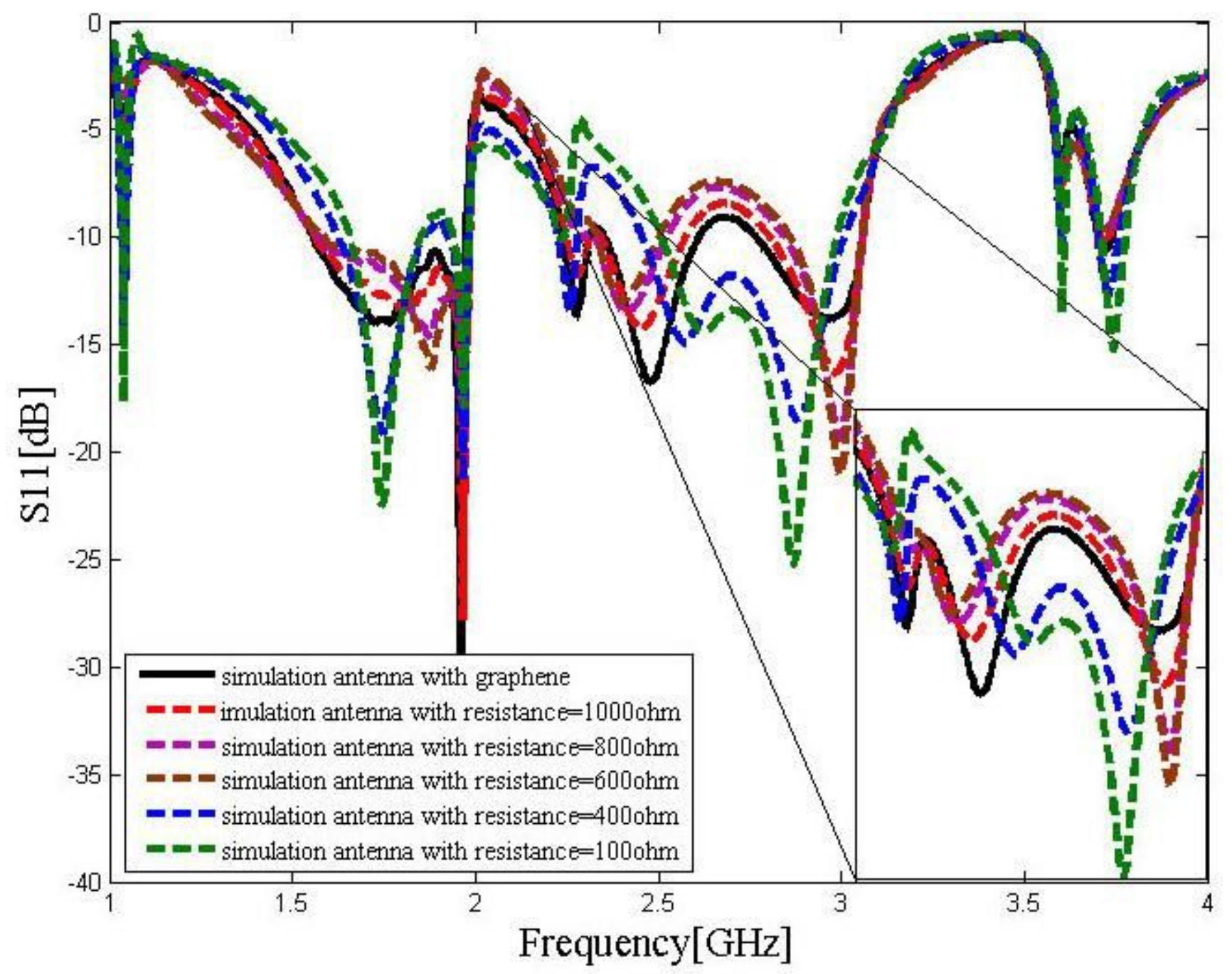

Figure 8

The simulation results of S11 versus frequency, for different values of the graphene equivalent resistance. 


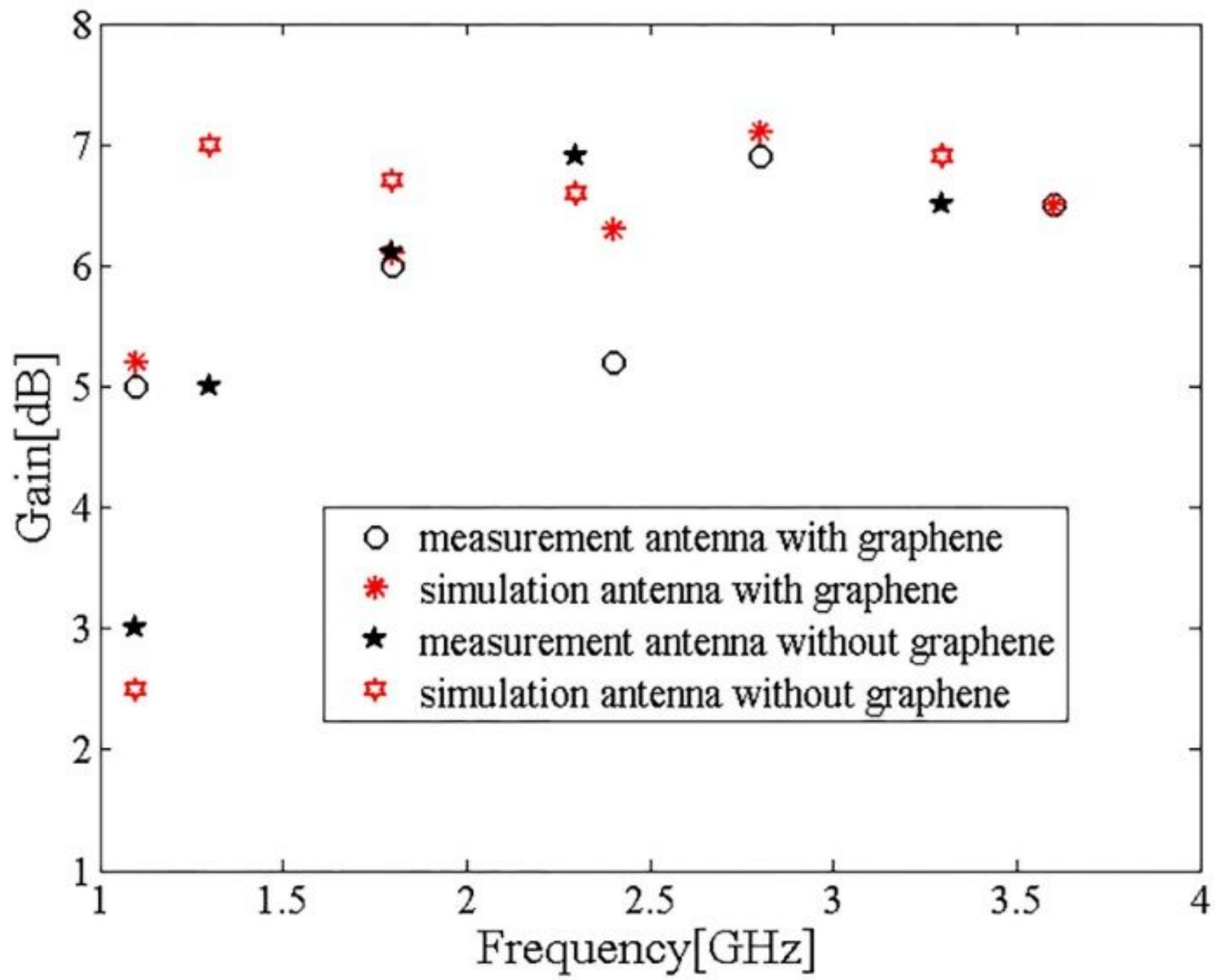

Figure 9

The simulation and measurement results of the gain for the proposed antennas. 


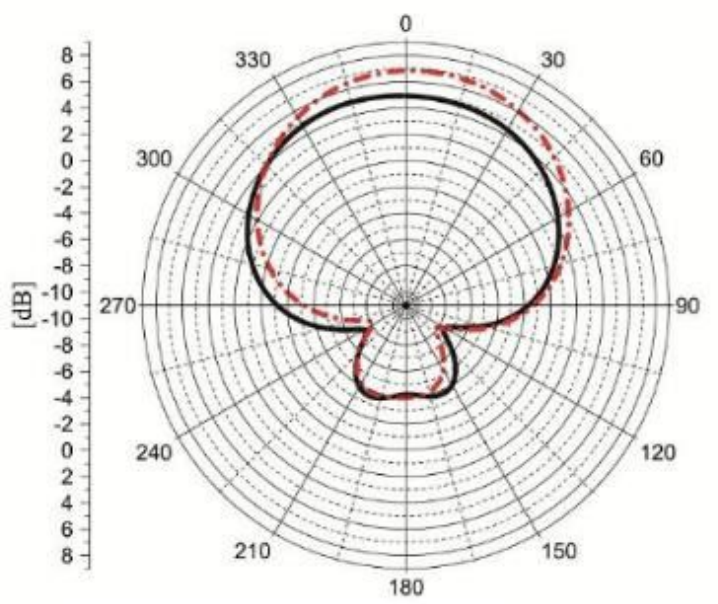

(a)

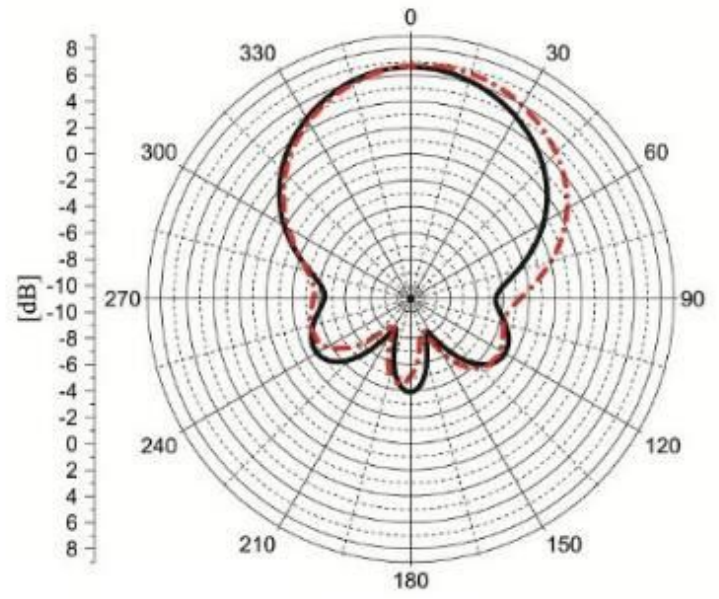

(c)

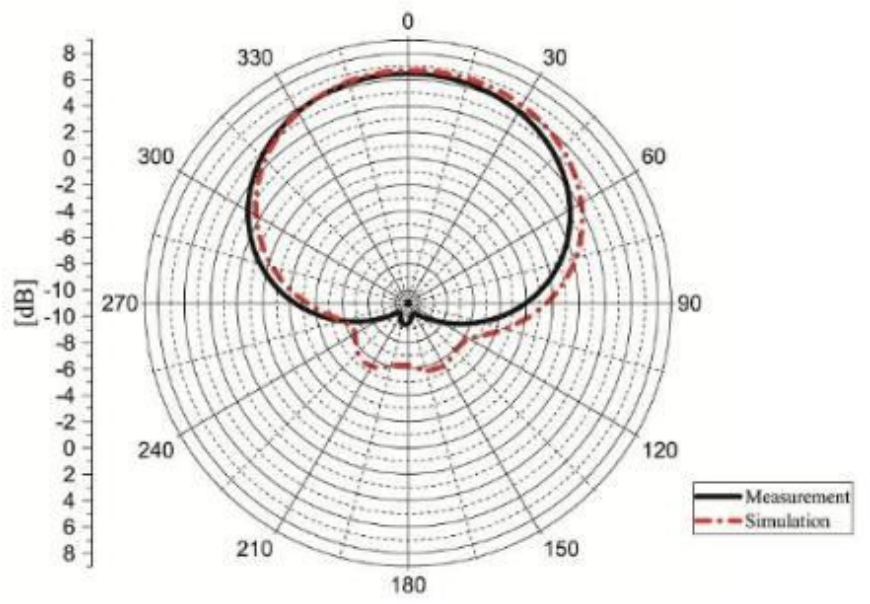

(b)

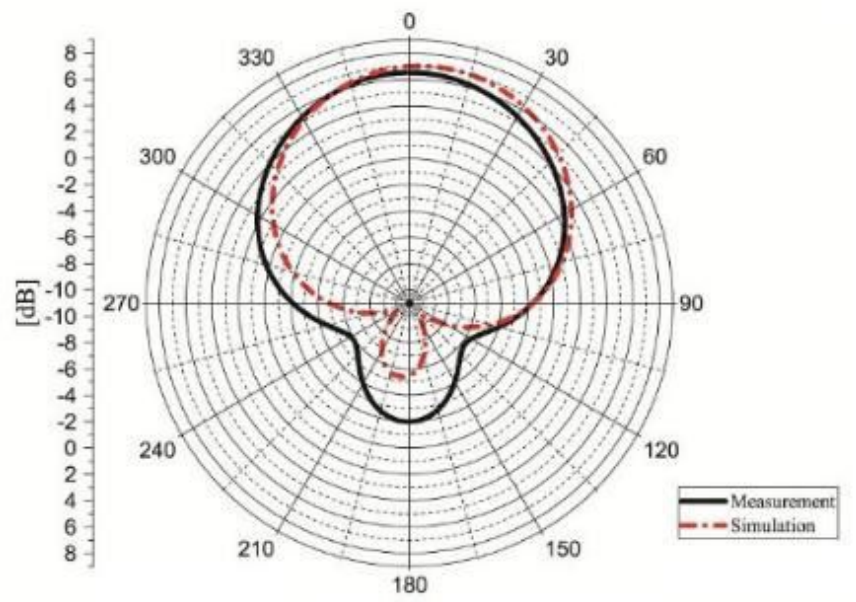

(d)

Figure 10

Measurement and Simulation results of the radiation pattern of the antenna without graphene. (a) $1.3 \mathrm{GHz},(\mathrm{b}) 1.8 \mathrm{GHz},(\mathrm{c}) 2.3 \mathrm{GHz},(\mathrm{d}) 3.3 \mathrm{GHz}$. 


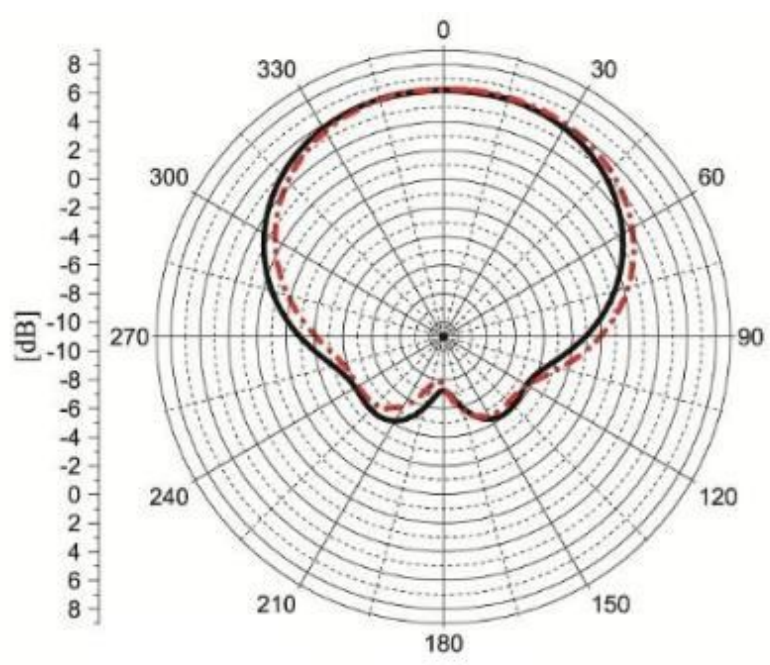

(a)

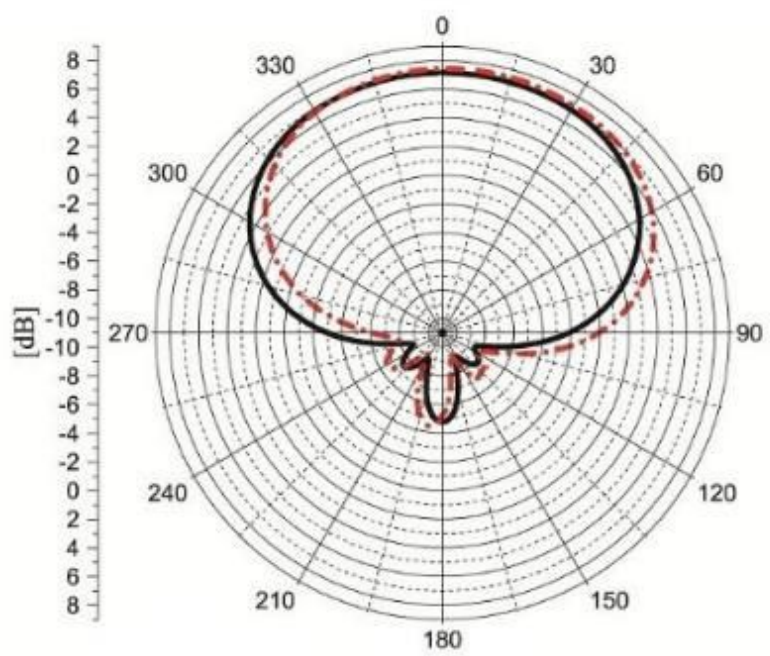

(c)

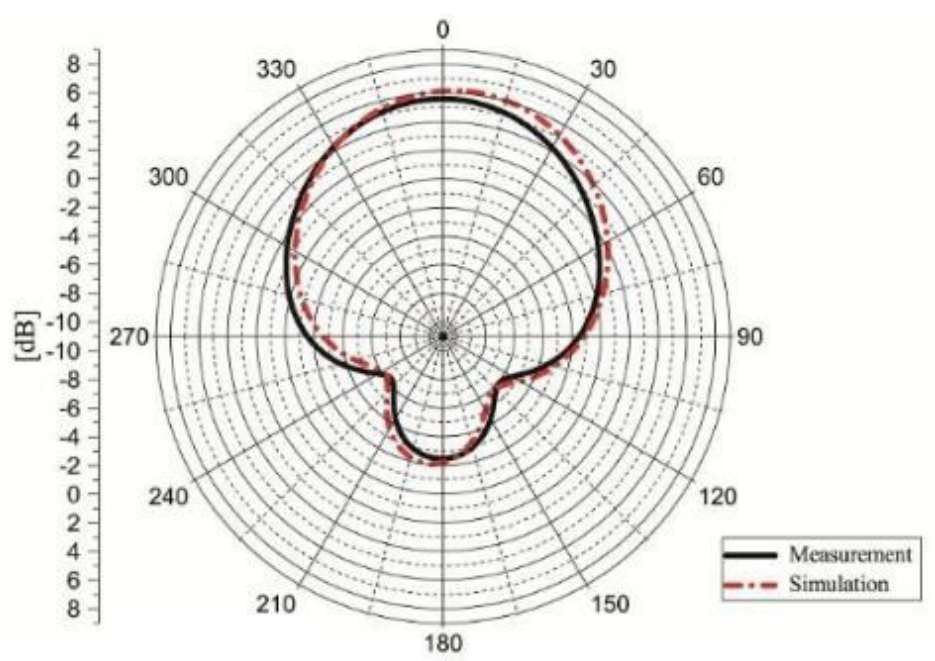

(b)

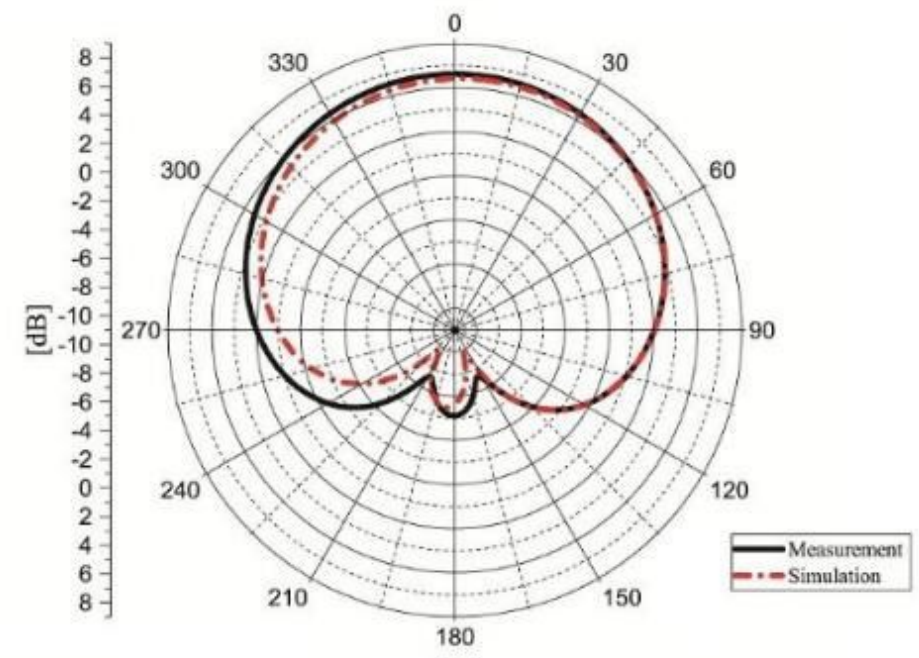

(d)

\section{Figure 11}

Measurement and Simulation results of the radiation pattern of the antenna with graphene. (a) $1.8 \mathrm{GHz}$, (b) $2.4 \mathrm{GHz},(\mathrm{c}) 2.8 \mathrm{GHz},(\mathrm{d}) 3.6 \mathrm{GHz}$.

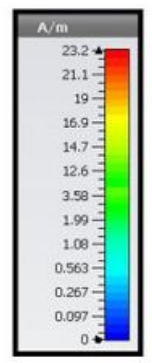

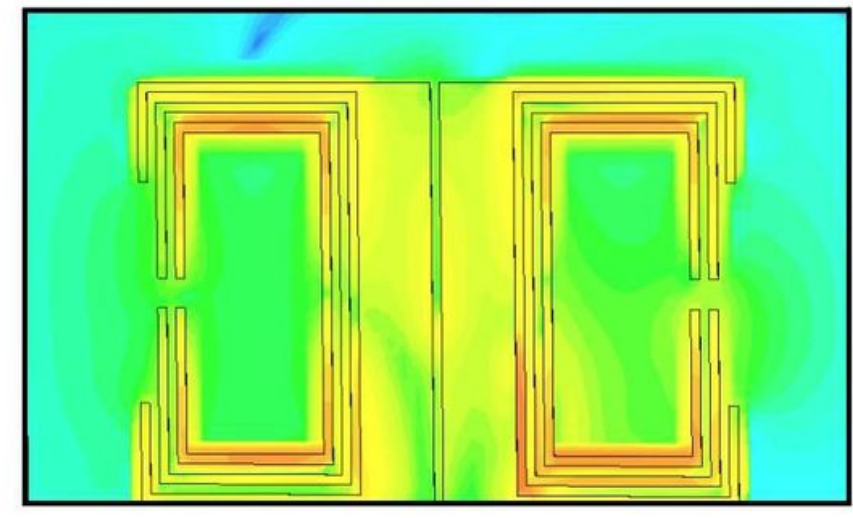

(a)

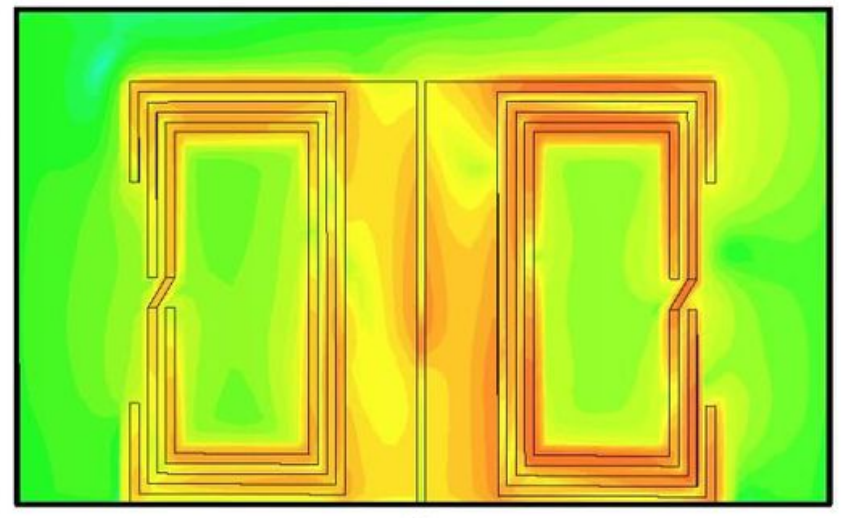

(b)

Figure 12 
Surface current distribution antenna (a) without graphene (b) with graphene. 